\title{
Rich Diseases in Poor Countries
}

\author{
Alireza Ansari-Moghaddam ${ }^{1^{*}}$, Mansour Shakiba ${ }^{2}$ \\ ${ }^{1}$ Health Promotion Research Center, Zahedan University of Medical Sciences, Zahedan, IR Iran \\ ${ }^{2}$ Department of psychiatry, Zahedan University of Medical Sciences, Zahedan, IR Iran
}

\section{A R T I C L E I N F O}

Article type: Editorial

\section{Article history:}

Received: 10 Oct 2012

Accepted: 23 Oct 2012

Keywords:

Chronic Disease

Developing Countries

Non-communicable diseases (NCDs) are becoming increasing prevalent worldwide and noticeably threaten health and longevity in developing countries (1-3). According to the WHO annual report, approximately $65 \%$ of 57 million deaths from all causes in 2009 were attributable to chronic disease including cancer, cardiovascular, diabetes, mental illness and pulmonary diseases $(1,2)$. Furthermore, this proportion is expected to increase by $69 \%$ in 2030 if the current trends continue without any change $(1,2)$. A longstanding assumption has been that chronic no communicable diseases are the problems of the rich and that the infectious, communicable, and maternal-fetal diseases are the problems of the poor countries (3). However, this belief is no longer true as the pattern of morbidity and mortality of NCDs are rapidly changing, with rates generally decreasing, or stabilizing, in developed countries but increasing in developing countries (1-3). Accordingly, the future burden of NCDs will not be equally shared by the world nations $(2,4)$. At present, the developing countries sheared less than half of the global burden of chronic diseases. By 2030, it is
- Implication for health policy/practice/research/medical education:

This manuscript provides a good understanding of life and death in an unequal world. It shows that why non-communicable diseases will place severe pressure on low and middle income countries in the area of inequality. Then, it could be of utmost importance for health policy makers.

- Please cite this paper as:

Ansari-Moghaddam A, Shakiba M. Rich Diseases in Poor Countries. Health Scope. 2012; 1 (3):96-8.

predicted that $70 \%$ of the global burden and $80 \%$ deaths due to NCDs will be borne by the developing world where these disease have traditionally had low incidence (2, 4 ). According to the recent estimates, the five aforementioned chronic non communicable diseases will cost US\$ 47 trillion over the next 20 years (2). Obviously, the developing countries are not like the developed nations and do not share the same opportunities to handle the huge amount of required budget $(2,4)$. For example, in Netherland, about $10 \%$ of the GNP is devoted to health care, while this is $2 \%$ at the most in the majority of developing countries (5).

In parallel well known existing, emerging, and reemerging diseases including tuberculosis, hepatitis, malaria, AIDS and others continue to be the major of morbidity and mortality in the developing countries (6-9). Notably, there is some evidence of associations between communicable and non-communicable diseases which contradict the separation of the two categories of the diseases among academic and health policy makers (6-9). For example, people with diabetes are seven times more likely to have

\footnotetext{
* Corresponding author: Alireza Ansari-Moghaddam, Health Promotion Research Center, Zahedan University of Medical Sciences, Zahedan, IR Iran. Tel +98-5412419403, Fax:+98-5412425375. E-mail: ansarialireza@yahoo.com
} 
culture-positive incident TB $(6,9)$. Consequently, the increased prevalence of diabetes in less developed regions may hinder efforts at TB control. Another importance issue is the worsening risk profile for diabetes and cardiovascular diseases in people on antiretroviral therapy for HIV infection (6). Accordingly, there will be a sizeable increase in the number of people with diabetes and cardiovascular disease especially in resource-poor settings.

Then, the increased prevalence and incidence of noncommunicable diseases along with common infectious diseases will place severe pressure on those countries with the least capability, capacity and small budget for health care to respond properly huge burden of health problems (1-10). More importantly, the dominance of the NCDs epidemic in developing countries has not been well recognized among health experts as these diseases are less visible than communicable diseases (1-10).

\section{Risk Factors: The Enemies to Combat}

The burden of non-communicable diseases are rapidly increasing in developing countries as a result of aging, increasing adoption of "westernized" lifestyle and high prevalence of tobacco use.

\section{Demographic Changes in Size and Age of Populations}

The first driver of increase in the burden of NCDs is aging of the population mainly due to global successes in improved life expectancy combined with a declining fertility rate (11-13). According to recent estimates, there has been a 20-year increase in the average life expectancy of the world's population during the second half of the last century, with another 10 year increment by 2050 likely (12). Consequently, the number of persons aged 65 years or older is estimated to double from 420 million (6.9\% of the global population) in 2000 to approximately 1 billion (12\% of the world population) by 2030 , and will approach $16.4 \%$ of the world's population by 2050 , with a sharp increase in developing countries due to their expanding population $(12,13)$. Importantly, persons over the age of 65 years are several times more likely to develop NCDs compared with individuals less than 65 years $(2,14,15)$.

\section{Increasing Tobacco Use}

Tobacco is the most important established modifiable risk factor for CVDs. Currently, about $80 \%$ of the 1.2 billion smokers live in low and middle income countries (LMIC), particularly in Asia, while smoking is falling in most developed countries (1) (16) 17). Notably, the smoking epidemic across large parts of Asia is relatively immature (by compared with countries such as the USA and UK where smoking reached its peak in the 1940's and 50's $(1,16,17)$. Therefore, there will be another 30 years before the full impact of smoking will become apparent because of the substantial time-lag between exposure to cigarette smoking and disease onset $(1,16,17)$.

\section{Changing Lifestyle Behaviors}

Over the past two decades, the percentage of urbanization has increased dramatically: among the total world population by $4 \%$, and even more so in East Asia and the Pacific, by $8 \%$ (18). Increased urbanization is often liked with the adoption of habits and lifestyles that tend to be hazardous to health including high fat and energy diets and sedentary lifestyles at the expense of traditional social and cultural habits $(3,19,20)$. For, example, traditional diet rich in fruit and vegetables are now being increasingly replaced by a diet rich in calories provided by animal -based products, more sugar as well as more processed foods and less fiber in all but the poorest countries $(3,19,20)$. In comparison, physical activity appears to be declining due to modernization, and changes in occupational behaviors $(3,19,20)$. Accordingly, there will be a considerable increase in overweight and obesity. Today, more than a billion adults are overweight, of which 300 million are clinically obese (21). Given that obesity and dietary habits represents potential risk factors for CVDs, type -2 diabetes and some types of cancer in absence of physical activity, it is non-surprising that the epidemic of overweight and obesity will be paralleled by the global epidemic of type-2 diabetes and consequently CVDs and cancer particularly in developing countries.

\section{Prevention and Control of NCDs in LMIC}

In conclusion, the primary prevention efforts focused on healthy diet, physical activity and the avoidance of tobacco smoking seems to be the three main pillars of NCDs prevention. The available data from the WHO and community-based intervention trials have come mainly from developed regions indicate that $80 \%$ of all the cases of CVDs and type-2 diabetes as well as $40 \%$ of all cancer cases could be prevented through abovementioned primary preventions (6). These experiences could be highly applicable in NCDs prevention and lifestyle modification in developing nations as well.

\section{Acknowledgments}

None declared.

\section{Authors' Contribution}

This study has been done equally by authors.

\section{Financial Disclosure}

None declared.

\section{Funding/Support}

None declared. 


\section{References}

1. Mathers CD, Loncar D. Projections of global mortality and burden of disease from 2002 to 2030. PLoS Med. 2006;3(11):e442.

2. Saxby MS. Diagnosis and treatment of juvenile periodontitis. Dent Update. 1988;15(3):116-9.

3. Nugent R. Chronic diseases in developing countries: health and economic burdens. Ann NY Acad Sci. 2008;1136:70-9.

4. Boutayeb A. The double burden of communicable and non-communicable diseases in developing countries. Trans $R$ Soc Trop Med Hyg. 2006;100(3):191-9.

5. Van den Bone B. Health promotion in developing countries: an interview with Bart van den Borne. Euro Health Psycho. 2009;11:23.

6. Unwin N, Alberti KG. Chronic non-communicable diseases. Ann Trop Med Parasitol. 2006;100(5-6):455-64.

7. Mascie-Taylor CG, Karim E. The burden of chronic disease. Sci. 2003;302:1921-2.

8. Snowden FM. Emerging and reemerging diseases: a historical perspective. Immunol Rev. 2008;225:9-26.

9. Goldhaber-Fiebert JD, Jeon CY, Cohen T, Murray MB. Diabetes mellitus and tuberculosis in countries with high tuberculosis burdens: individual risks and social determinants. Int J Epidemiol. 2011;40(2):417-28.

10. Reinsch N, Neuhaus K, Esser S, Potthoff A, Hower M, Mostardt $\mathrm{S}$, et al. Are HIV patients undertreated? Cardiovascular risk factors in HIV: results of the HIV-HEART study. Eur J Prev Cardiol. 2012;19(2):267-74.
11. UN lowers projection on future population growth.Janasamkhya Siksha Mukhapatra. 1999;8(1):15.

12. Trends in aging--United States and worldwide. MMWR Morb Mortal Wkly Rep. 2003;52(6):101-4, 6.

13. Diczfalusy E. The demographic revolution and our common future. Maturitas. 2001;38(1):5-14; discussion -5.

14. Yancik R, Ries LA. Cancer in older persons. Magnitude of the problem-how do we apply what we know? Cancer. 1994;74(7 Suppl):1995-2003.

15. Yancik R. Population aging and cancer: a cross-national concern. Cancer J. 2005;11(6):437-41.

16. Peto R, Lopez AD, Boreham J, Thun M, Heath CJ, Doll R. Mortality from smoking worldwide. Br Med Bull 1996;52(12-21).

17. Liu BQ, Peto R, Chen ZM, Boreham J, Wu YP, Li JY, et al. Emerging tobacco hazards in China: 1. Retrospective proportional mortality study of one million deaths. BMJ.1998;317:1411-22.

18. Lopez AD, Begg S, Bos E. Demographic and Epidemiological Characteristics of Major Regions, 1990-2001. 2006.

19. Amuna P, Zotor FB. Epidemiological and nutrition transition in developing countries: impact on human health and development. Proc Nutr Soc. 2008;67(1):82-90.

20. Reddy KS, Yusuf S. Emerging epidemic of cardiovascular disease in developing countries. Circulation. 1998;97(6):596-601.

21. World health organization. Obesity and overweight. In global strategy on diet, physical activity and health. Geneva; 2003; Available from: http://www.who.int/dietphysicalactivity/media/ en/gsfs_obesity.pdf. 